\section{Some important points for urodynamic studies}

Ürodinamik araştırmalarda dikkate değer konular

Selçuk Sayılır

Department of Physical Medicine and Rehabilitation, Medical Faculty of Muğla Sitkı Koçman University, Muğla, Turkey

Received / Geliş tarihi: April 2016 Accepted / Kabul tarihi: May 2016

\section{Dear Editor,}

I have taken a great interest in the recently published article entitled "Urodynamic findings in stroke patients with overactive bladder symptoms" by Aydemir et al. ${ }^{[1]}$ However, I have a few remarks with respect to the methodology used in the study.

First, the medical treatments which the patients previously used (anticholinergic, alpha blocker and baclofen) were not recorded in the study. This factor can affect detrusor hyperactivity, sphincter activity, voided volume and residual volume. ${ }^{[2]}$ For example, alpha blockers are prescribed in order to support and enhance the preserved emptying function. On the other hand, prescribed anticholinergic can affect the severe storage and emptying dysfunction of the bladder and improve bladder capacity. ${ }^{[3]}$ Another, effective drug is baclofen, which has a positive effect on the bladder emptying function by relaxing the external sphincter. ${ }^{[4]}$ This drug is commonly used in stroke patients.

The emptying methods and duration could affect bladder function. Long time use of catheters can cause severe morbidities in the bladder and in the functions of the bladder such as chronic infections, bladder stones, cancer etc., these problems can have a serious affect on the bladder and its functions.

The spasticity levels of patients which can cause changes in the outcomes of the study were not recorded. A higher rate of spasticity can effect detrusor activity. ${ }^{[5]}$ An explanation of the measuring technique of residual volume was also not recorded in the methods' section.
This can lead to variable outcomes based on the technique used to measure (sonographic measurement or measurement with catheters) as well as depending on the person who is doing the measurements.

\section{Declaration of conflicting interests}

The author declared no conflicts of interest with respect to the authorship and/or publication of this article.

\section{Funding}

The author received no financial support for the research and/or authorship of this article.

\section{REFERENCES}

1. Aydemir K, Adıgüzel E, Yılmaz B. Urodynamic findings in stroke patients with overactive bladder symptoms. Turk J Phys Med Rehab 2016;1:51-6.

2. Cameron AP. Medical management of neurogenic bladder with oral therapy. Transl Androl Urol 2016;5:51-62.

3. Sayılır S, Ersöz M, Yalçın S. Comparison of urodynamic findings in patients with upper and lower cervical spinal cord injury. Spinal Cord 2013;51:780-3.

4. Chin HY, Lin KC, Chiang CH, Wang CJ. Combination of baclofen and antimuscarinics to reduce voiding difficulty in treating women with overactive bladders. Clin Exp Obstet Gynecol 2012;39:171-4.

5. Kirshblum S. Rehabilitation of SCI. In: DeLisa JA, Gans BM, editors. Physical Medicine and Rehabilitation, Principles and Practice. 4th ed. Philadelphia: Lippincott Williams \& Wilkins; 2005. p. 1715-51.

\section{Author Reply}

\section{Dear Editor,}

In the article which we authored, ${ }^{[1]}$ the main focus was to determine the effect of the localization of the brain lesion on bladder function in patients with stroke. We agree with the authors of the letter regarding the effects of medications, emptying methods and spasticity level on urodynamic findings. In addition to medications, we can add many other variables such as hydration, equipment calibration, catheter size, patient position, etc. These factors can be interpreted as confounding factors in urodynamic studies. It is not possible to control for all of them in such studies and one should not forget that for ethical considerations, 
cessation of these medications would be inconvenient. Additionally, in the conclusion section of the paper, we expressed that there are not any large-scale longitudinal studies investigating lesion localizationbladder interactions and that further prospective studies are necessary.

The authors of the letter claimed that the measuring technique for residual volume was not explained. Residual volume data was obtained using multi-channel urodynamic equipment and this was expressed in the $4^{\text {th }}$ paragraph of the patients and methods section.

We realize that the authors of the letter cited papers and chapters about spinal cord injury when commenting on the findings of our paper but we would like to remind them that our study was strictly about patients with stroke.

In conclusion, we would like to emphasize that the most important thing for clinicians to do is to properly interpret urodynamic results and to consider the entire clinical picture of the patient when making a decision.

\section{REFERENCES}

1. Aydemir K, Adıgüzel E, Yılmaz B. Urodynamic findings in stroke patients with overactive bladder symptoms. Turk J Phys Med Rehab 2016;1:51-6.

Correspondence: Emre Adıgüzel, MD. Gülhane Askeri Tıp Akademisi, TSK Rehabilitasyon Merkezi, 06530 Bilkent, Ankara, Turkey.

e-mail: dremreadiguzel@gmail.com 